\title{
Analysis of Concrete-Filled Steel Tube Reinforced Concrete Column-Steel Reinforced Concrete Beam Plane Frame Structure Subjected to Fire
}

\author{
Yanhong Bao $\mathbb{D}^{\mathrm{D}},{ }^{1,2}$ Bowen Chen, ${ }^{1,2}$ and Lei $\mathrm{Xu}^{3}$ \\ ${ }^{1}$ School of Civil Engineering, Qinghai University, Xining, China \\ ${ }^{2}$ Qinghai Provincial Key Laboratory of Energy-saving Building Materials and Engineering Safety, Qinghai University, \\ Xining, China \\ ${ }^{3}$ School of Civil Engineering, Dalian Nationalities University, Dalian, China
}

Correspondence should be addressed to Yanhong Bao; cebaoyh@163.com

Received 19 November 2020; Revised 28 February 2021; Accepted 23 March 2021; Published 8 April 2021

Academic Editor: Melina Bosco

Copyright (C) 2021 Yanhong Bao et al. This is an open access article distributed under the Creative Commons Attribution License, which permits unrestricted use, distribution, and reproduction in any medium, provided the original work is properly cited.

\begin{abstract}
The ABAQUS finite-element analysis platform was used to understand the mechanical behavior of concrete-filled steel tube reinforced concrete (CFSTRC) columns and steel reinforced concrete (SRC) beam plane frames under fire conditions. Thermal parameters and mechanical constitutive model of steel and concrete materials were reasonably selected, the correct boundary conditions were chosen, and a numerical model for the thermal mechanical coupling of CFSTRC columns and SRC beam plane frame structure was established. The finite-element model was verified from related experimental test results. The failure modes, deformation, and internal force distribution of the CFSTRC column and SRC beam plane frames were analyzed under ISO-834 standard fire conditions and with an external load. The influence of beam and column fire-load ratio on the fire resistance of the frame structure was established, and the fire-resistance differences between the plane frame structures and columns were compared. The CFSTRC column-steel reinforced concrete beam plane frame may undergo beam failure or the column and beam may fail simultaneously. The frame structure fire-resistance decreased with an increase of column and beam fire-load ratio. The column and beam fire-load ratio influence the fire resistance of the frames significantly. In this numerical example, the fire resistance of the frames is less than the single columns. It is suggested that the fire resistance of the frame structure should be considered when a fire-resistant structural engineering design is carried out.
\end{abstract}

\section{Introduction}

Concrete-filled steel tube reinforced concrete (CFSTRC) column and steel reinforced concrete (SRC) beam plane frame structures are composed of joined CFSTRC columns and SRC beams. This type of frame structure combines all advantages of CFSTRC columns and SRC beams perfectly and so has been applied extensively to high-rise and superhigh-rise buildings [1]. Along with its extensive application, the fire-resistance capacity of CFSTRC column-SRC beam frame structures has attracted attention from an increasing number of researchers.

In recent years, many scholars have studied the fire resistance of columns, steel structures, reinforced concrete frame structures, and concrete-filled steel tube frame structures. Espinos et al. [2-5] studied the fire resistance of composite columns. Rodrigues et al. [6, 7] carried out experimental study on the fire resistance of restrained composite columns. Kodur et al. [8, 9] studied the fire resistance of composite columns under heterogeneous fire. Ding et al. [10] analyzed the capacity of steel frame columns on fire and considered that the axial force of the steel beams has an adverse effect on the fire resistance of frame columns. Li et al. $[11,12]$ studied the fire resistance of $\mathrm{H}$-section steel beams and steel frame structures and showed that the failure modes of steel frame structures on fire differ from those of single steel column specimens. Lu et al. [13] studied the mechanical behavior of reinforced concrete frame structures on fire, and 
showed that the thermal expansion of frame structures generates internal forces and accelerates the destruction of reinforced concrete frames. Wu et al. [14] studied the mechanical behavior of reinforced concrete spatial frames with special-shaped columns on fire and inspected the failure modes and deformation of key parts of reinforced concrete frame structures. Wang et al. $[15,16]$ studied the failure modes, failure mechanism, deformation, and redistribution of internal force of concrete-filled steel tubular column-steel beam plane frames under local fire conditions. Wang et al. [17] carried out an experimental study and finiteelement analysis of the mechanical response of concretefilled steel tube column-SRC beam plane frames on fire. Bao et al. [18] analyzed the fire resistance of CFSTRC columnreinforced concrete beam plane frames by finite-element methods. The above research showed that the thermal effect was significant on the deformation and internal force of the frame structure on fire because of the statically indeterminate frame structure. CFSTRC column-SRC beam frame structures have been used extensively in engineering practice. It is necessary to study the fire resistance of these frame structures because of their continuous popularization and application.

Because of the complexity of fire tests and difficulties with measuring internal structural forces, this work considered CFSTRC column-SRC beam frame structures as the analysis object and used a finite-element method to analyze the mechanical properties of the CFSTRC column-SRC beam frame structures under the combined action of load and fire and to provide reference for fire-resistant design of frame structure in projects.

\section{Finite-Element Analysis Model}

2.1. Model Establishment. To simulate the heat transfer and deformation between CFSTRC column-SRC beam plane frame structures (hereinafter referred to as the "composite column frame structure") and surrounding fires, a finiteelement temperature model and mechanical model of the composite column frame structure was established by using the thermal mechanical coupling module of the ABAQUS finite-element software.

We used an 8-node linear heat-transfer brick (DC3D8 element) to simulate the steel tube, concrete, section steel, and base plate and a 2-node heat-transfer link (DC1D2) to simulate the steel bar in the temperature model of composite column frame structure. To simulate the fire action, the ISO834 [19] international standard heating curve was used for the lower part of the steel concrete floor and around the CFSTRC columns. The initial temperature and absolute zero temperature were defined as 20 and $-273^{\circ} \mathrm{C}$, respectively, and the Stefan-Boltzmann constant was set to $5.67 \times 10^{-8} \mathrm{~W} /\left(\mathrm{m}^{2} \cdot \mathrm{K}^{4}\right)$. During the fire action, heat circulates on the surface of the composite column frame structure through radiation and convection. The heat convection coefficient was taken as $25 \mathrm{~W} /\left(\mathrm{m}^{2} .{ }^{\circ} \mathrm{C}\right)$ and the surface radiation emissivity was selected as 0.5 [20]. To ensure that the joint temperature of the different materials was the same at the same geometric position, a tie constraint was used between the steel tube, section steel, reinforcement, and concrete.

We used the steel and concrete thermal parameters expressed by Lie [21], who obtained good accuracy verification in previous fire-resistance research results on columns. The temperature field calculations of the CFSTRC column considered the influence of water vapor in the concrete specific-heat calculations, according to Lie [21] and Lie and Chabot [22]; the concrete quality was assumed to have a moisture content percentage of $5 \%$, and the modified specific heat of the concrete was

$$
\begin{aligned}
\rho_{c}^{\prime} c_{c}^{\prime} & = \begin{cases}0.95 \rho_{c} c_{c}+0.05 \rho_{w} c_{w}, & T<100, \\
\rho_{c} c_{c}, & T \geq 100,\end{cases} \\
\rho_{w} c_{w} & =4.2 \times 10^{6} \frac{\mathrm{J}}{\left(\mathrm{m}^{3} \cdot{ }^{\circ} \mathrm{C}\right)},
\end{aligned}
$$

where $\rho_{c}^{\prime}$ and $c_{c}^{\prime}$ are the bulk density and specific heat of concrete considering the influence of water vapor, respectively, $\rho_{c}$ and $c_{c}$ are the bulk density and specific heat of concrete without considering the influence of water vapor, respectively, and $\rho_{w}$ and $c_{w}$ are the density and specific heat of water, respectively.

A thermal-mechanical sequentially coupled mechanics model for the composite column frame structure was established based on the established temperature field analysis model for the composite column frame structure. Solid elements (C3D8) were used for the base plate, steel pipe, section steel, reinforced concrete, and core concrete, whereas truss elements (T3D2) were used for the steel bars. The interface between the steel bars and the reinforced concrete outside of the CFST and the steel bars and floor slab concrete were assumed to have the ability to hold together without slippage. Hard contact was used in the normal direction, and a Coulomb friction coefficient of 0.6 [23] was used in the tangential direction to consider the slippage between the steel tube and the concrete, the section steel, and the concrete in the interior and exterior of the steel tube. The base plate and ends of the concrete and steel pipe were tied. The initial imperfections of frame columns have been included in the mechanical model when the frame columns conducted mechanical analysis under axial load. The calculation results of the temperature field must be imported into the mechanical model correctly to maintain consistent meshes between the mechanical model and the temperature field thermal analysis model.

We used the steel stress-strain models by Lie and Chabot [22] and the thermal expansion models for steel and concrete proposed by Lie [21]. Figures 1 and 2 illustrate the stress-strain relationship of steel (Q345) and the thermal expansion models of steel and concrete at different temperatures, respectively. The compressed stress-strain relationship models of the core concrete and reinforced concrete under fire were selected from Han [23] and Lie [21], as shown in formulae (1) and (2), respectively. In the stressstrain relationship of core concrete, the influence of steel tube restraint on concrete plastic deformation was 


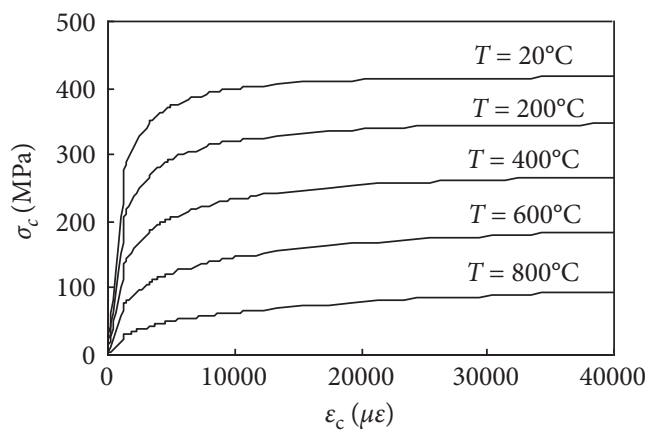

Figure 1: Stress-strain relationship of steel at high temperature.

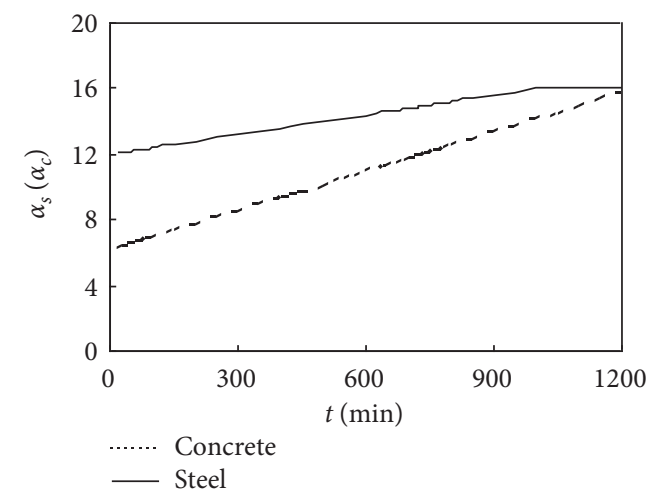

section of stress-strain curve of core concrete. Figure 3 presents the stress-strain relationship of C40 concrete under compression at different temperatures.

The compressed stress-strain relationship models of the core concrete under fire:

$$
y= \begin{cases}2 x-x^{2}, & x \leq 1, \\ \frac{x}{\beta(x-1)^{2}+x}, & x>1,\end{cases}
$$

Figure 2: Thermal expansion coefficient of material.

considered. The steel tube restraint effect affects the plastic deformation of core concrete, especially the descending

where $x=\left(\varepsilon / \varepsilon_{0}^{T}\right)$ and $y=\left(\sigma / \sigma_{0}^{T}\right)$.

$$
\begin{aligned}
\sigma_{0}^{T} & =\frac{f_{c}^{\prime}}{\left[1+a(T-20 / 1000)^{b}\right]}, a=0.017 f_{c}^{\prime}+7.83 ; b=-0.016 f_{c}^{\prime}+3.77, \\
\beta & =\left\{\begin{array}{l}
\left(2.36 \times 10^{-5}\right)^{\left[0.25+(\xi-0.5)^{7}\right]} \cdot f_{c}^{0^{\prime} .5} \cdot 0.5 \geq \beta_{T}, \\
\frac{\left(f_{c}^{\prime}\right)^{0.1}}{1.2 \sqrt{1+\xi}}, \quad \text { round steel tube concrete, }
\end{array}\right. \\
\beta_{T} & =0.35-\frac{0.25}{1+1.2 \times 10^{4} \cdot(T+190 / 1000)^{11},} \quad \text { square and rectangular steel tube concrete, }
\end{aligned}
$$




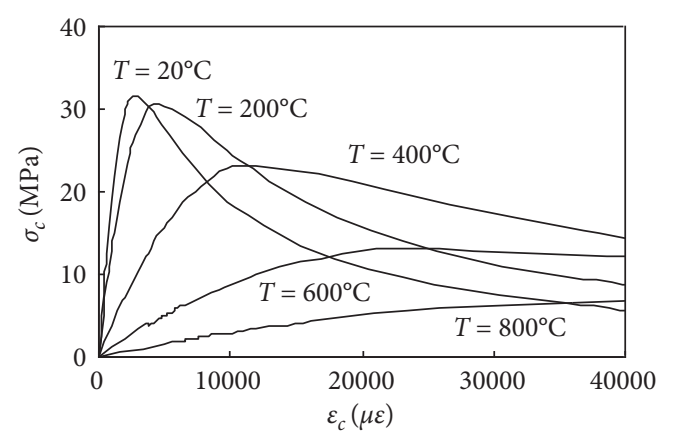

(a)

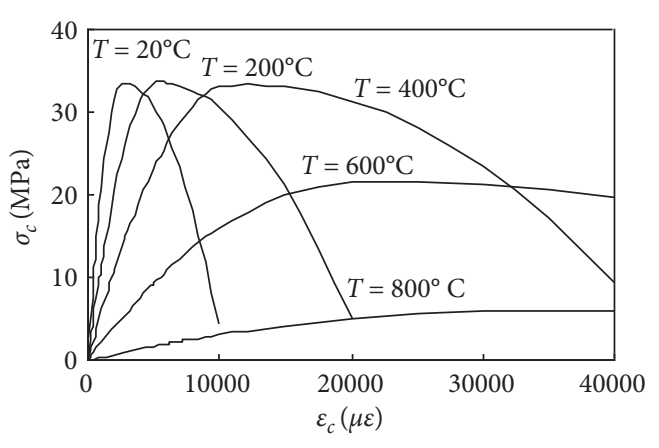

(b)

FIGURE 3: Stress-strain relationship of concrete at high temperature. (a) Core concrete. (b) Reinforced concrete.

The compressed stress-strain relationship models of the reinforced concrete under fire:

$$
\sigma_{c \sigma}= \begin{cases}f_{c}^{\prime}(T)\left[1-\left(\frac{\varepsilon_{o h}-\varepsilon_{c \sigma}}{\varepsilon_{o h}}\right)^{2}\right], & \varepsilon_{c} \leq \varepsilon_{o h}, \\ f_{c}^{\prime}(T)\left[1-\left(\frac{\varepsilon_{c \sigma}-\varepsilon_{o h}}{\varepsilon_{o h}}\right)^{2}\right], & \varepsilon_{c}>\varepsilon_{o h},\end{cases}
$$

where $\varepsilon_{o h}=0.0025+\left(6 T+0.04 T^{2}\right) \times 10^{-6}$,

$$
f_{c}^{\prime}(T)= \begin{cases}f_{c}^{\prime}, & 0^{\circ} \mathrm{C}<T \leq 450^{\circ} \mathrm{C}, \\ f_{c}^{\prime}\left[2.011-2.353\left(\frac{T-20}{1000}\right)\right], & 450^{\circ} \mathrm{C} \leq T \leq 874^{\circ} \mathrm{C}, \\ 0, & T>874^{\circ} \mathrm{C}\end{cases}
$$

where $\varepsilon_{o h}$ is the peak strain of concrete and $f_{c}^{\prime}(T)$ is the compressive strength of concrete cylinder at temperature $T$.

The finite-element model of the composite column plane frame structure is shown in Figure 4.

2.2. Validation of FEA Model. To verify the correctness of the numerical model, the finite-element method was applied to two concrete-filled steel tube columns and SRC beam frame structures CFSRC- 1 and CFSRC-2 models from Wang [17]; the results were compared with the test results.

Figure 5 shows the geometric dimensions and frame structures models of the CFSRC- 1 and CFSRC- 2 by Wang [17]. The section specification of the circular steel pipe was $\bigcirc$ $140 \mathrm{~mm} \times 3.85 \mathrm{~mm}$, the material yield strength was $f_{y}=412 \mathrm{MPa}$, and the column height was $1456 \mathrm{~mm}$. The model CFSRC-1 and CFSRC-2 columns were coated with 3 and $6 \mathrm{~mm}$-thick fire-retardant coatings, respectively, and the thermal parameters of the fire-retardant coating were as follows: the density $\rho=(400 \pm 20) \mathrm{kg} / \mathrm{m}^{3}$, the thermal conductivity $k=0.097 \mathrm{~W} /\left(\mathrm{m} \cdot{ }^{\circ} \mathrm{C}\right)$, and the specific $c=1.047 \times 10^{3} \mathrm{~J} /\left(\mathrm{kg} \cdot{ }^{\circ} \mathrm{C}\right)$. SRC beams were $\mathrm{T}$-shaped beams with cross-sectional dimensions of $h_{b} \times b_{b}=160 \mathrm{~mm} \times 110$ $\mathrm{mm}$. H-section steel was H $80 \mathrm{~mm} \times 30 \mathrm{~mm} \times 4 \mathrm{~mm} \times 4 \mathrm{~mm}$ and the yield strength of the $\mathrm{H}$ steel was $f_{y}=269.1 \mathrm{MPa}$. The upper and lower reinforcement of the beam was $2 \phi 10$, the yield strength of the reinforcement was $f_{y}=445.9 \mathrm{MPa}$, the section size of the concrete floor was $600 \mathrm{~mm} \times 60 \mathrm{~mm}$, and the measured cube compressive strength of the concrete during the test was $f_{c u}=56.7 \mathrm{MPa}$. The concentrated loads at the upper three points of the beam in the model CFSRC-1 and CFSRC- 2 were $36 \mathrm{kN}$ and $18 \mathrm{kN}$, respectively, and the axial load of the column was $380 \mathrm{kN}$. Figure 6 compares the calculated results of the temperature field of the CFSRC-1 and CFSRC-2 beam-slab midspan section and the experimental results by Wang [17]. The calculated results of the temperature field agreed well with the experimental results, and errors at individual points were slightly larger in Figure 6 because some temperature measuring points moved during Wang's test [17]. Figure 7 compares the calculated results of the CFSRC-1 and CFSRC-2 column top axial displacement, the deflection-time curves at different measuring points on the beam, and the test results by Wang [17]. The calculated vertical displacement-time curves of model CFSRC-1 and CFSRC-2 agree well with the experimental results, and the fire-resistance limits of the calculation and test are close in Figure 7.

\section{Fire-Resistance Analysis}

3.1. Finite-Element Model. A plane frame structure with single-layer and single span concrete-filled steel tube reinforced column-steel reinforced concrete beam is designed by referring to the common concrete-filled steel tube hoop 


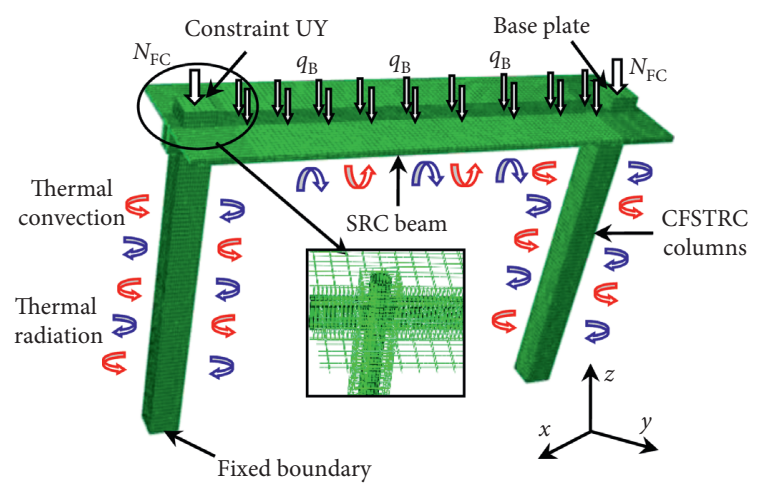

FIGURE 4: FEA model of composite frame.

index, steel ratio, and cross-section core area ratio in [24-26]. Figure 8 presents the geometric dimensions and construction of the composite column frame structure. The joints of the composite column frame structure are designed as rigid joints according to the requirements of joint construction in [26]. A concentrated load was applied on the top of the frame column, and the load value was applied according to the column fire-load ratio. A uniform surface load was applied to the beam, and the load value was applied according to the beam fire-load ratio. The fire-load ratio means the ratio of the load acting on the member under fire and the ultimate bearing capacity of the member at room temperature. In the standard example, the column fire-load ratio $n_{c}$ was $0.6, N_{F C}=9900 \mathrm{kN}$, the beam fire-load ratio $n_{b}$ was 0.6 , and $\varepsilon_{B}=160 \mathrm{kN} / \mathrm{m}^{2}$. The finite-element model is shown in Figure 4.

\subsection{Calculation Analysis}

3.2.1. Failure Modes of Composite Column Frame Structures. The failure criteria to determine the fire-resistance limit of components in ISO-834 [19] were used for the fire-resistance limit of the composite column frame structures: (1) the maximum beam and slab deflection reached $L^{2} /(400 h)$ or the deformation rate exceeded $L^{2} /(400 h)$, where $L$ was the beam and slab calculated span and $h$ was the beam section height; (2) the axial compression of the column reached $0.01 \mathrm{H}$ or the axial compression rate exceeded $0.003 \mathrm{H}$, where $H$ was the column fire height; it was assumed that when the frame beam or column reached the deformation limit state under fire, the composite column frame structure reached the fire-resistance limit.

Table 1 presents the influence of fire-load ratio of the frame beam and column on the failure mode and fire-resistance limit of the composite column frame structure. The influence of a single factor of the column fire-load ratio or beam fire-load ratio on the overall fire-resistance limit of the composite column frame structure was considered. Table 1 shows that when the fire-load ratio of the beams remained unchanged, the overall fire-resistance limit of the composite column frame structure decreased with an increase in the column fire-load ratio and the failure type of the frame structure changed from the beam broke down to the frame beam and frame column which were destroyed simultaneously. When the fire-load ratio of the column remained unchanged, the overall fire-resistance limit of the composite column frame structure decreased with an increase in the fire-load ratio of the beam, and the frame beam and frame column were destroyed simultaneously. Table 1 shows that the column fire-load ratio had a greater impact on the overall fire-resistance limit of the composite column frame structure than the beam fire-load ratio, and the failure mode of the frame structure changed from the beam broke down to the frame beam and frame column which were destroyed simultaneously.

Figure 9 shows that the failure mode of the composite column frame structure reached the fire-resistant limit time when the column fire-load ratio was 0.6 and the beam fireload ratio was 0.6 .

When the composite column frame reached the fireresistance limit under fire and load, the frame beam bent downwards and the frame column bent outwards (as shown in Figure 9). When the frame reached the fire-resistance limit, large plastic deformation occurred at the inner side of the top of the column, the outer side of the bottom of the column, and the cross section of the middle and bottom of the beam span.

\subsubsection{Deformation of Composite Column Frame.}

Figure 10 shows the deformation versus time curves of the top axis of the frame column and the midspan section of the frame beam of a composite column frame structure under different column fire-load ratios. In Figure 10, the axial deformation and elongation of the top of the frame column are positive, and the upward deformation of the midspan deflection of the frame beam is positive.

Figure 10(a) shows that, with an increase of fire time, the deformation of the frame column top increases. With the increase of the column fire-load ratio, the fire-resistance limit of the frame decreases, and the deformation of the column top develops rapidly. With a decrease of column fire-load ratio, the axial expansion deformation of the frame column top increases. When the column fire-load ratio is 0.2 and when the frame reaches the fire-resistance limit, the axial deformation of the column top remains in the expansion stage. Figure 10(b) shows that, with an increase of fire time, the midspan deflection of the frame beam increases. With a decrease of the column fire-load ratio, the overall frame structure fire-resistance limit increases, and the change rate of the midspan deflection of the frame beam decreases.

\subsubsection{Force Distribution of Composite Column Frame} Structure. Under the action of fire, the components of the composite column frame structure will produce high-temperature expansion deformation because the expansion deformation cannot be deformed freely because of the constraint between adjacent components. Therefore, internal force will be generated in the components. At the same time, the mechanical properties of the steel and concrete materials deteriorate gradually with an increase of fire time, 


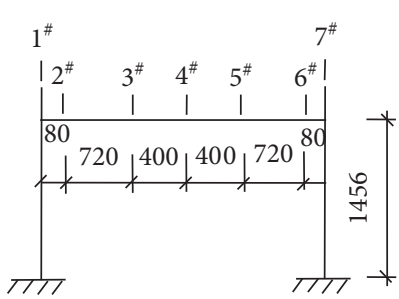

(a)

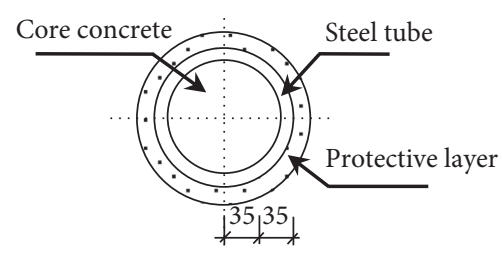

(b)

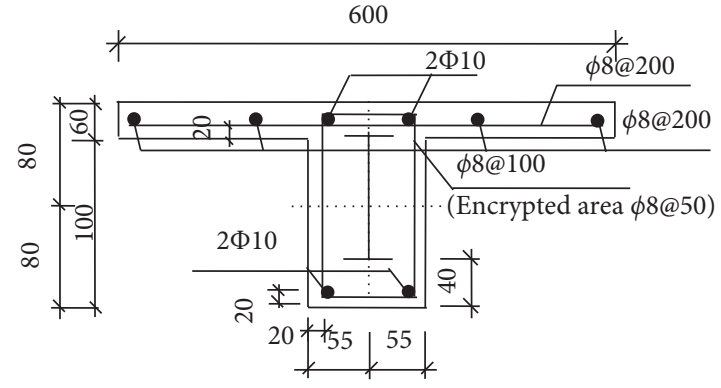

(c)

Figure 5: Geometric size and details of CFSRC-1 and CFSRC-2 models. (a) Layout of displacement measure. (b) Section size of concretefilled steel tube columns. (c) Medium-span section size of SRC beams.

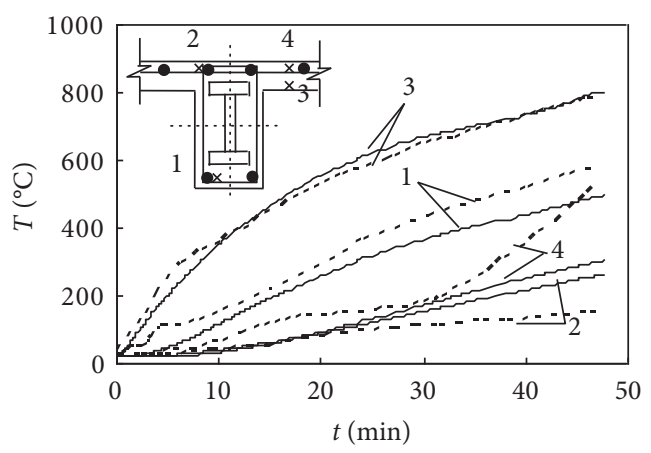

(a)

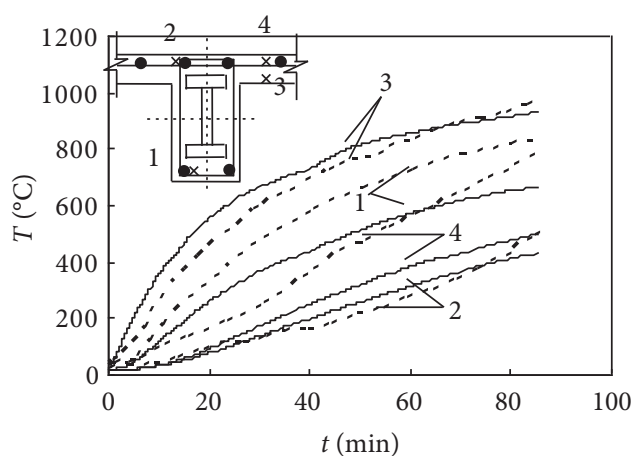

(b)

Figure 6: Temperature curves of middle section of model beam. (a) Model CFSRC-1. (b) Model CFSRC-2.

which changes the mechanical properties of the composite column frame structure and redistributes the internal forces of the composite column frame structure.

Figures 11 and 12 show curves of the internal force of the frame beam section at the midspan of the frame beam and the node area with the time of fire. The bending moment makes the tension of the lower part of the beam positive and the tension of the upper part negative. The axial force makes the tension of the frame beam positive and the pressure negative. The shear force makes the clockwise rotation of the beam end positive and the anticlockwise rotation negative. Figure 11(a) shows that the bending moment of the midspan section of the frame beam decreases slightly in the early stage of fire, but it does not change much. After 4 min of fire, the bending moment increases gradually with an increase of fire time because, in the early stage of fire, the lower part of the frame beam is subjected to fire. Along the height of the beam section, the temperature at the bottom is higher and the upper part is lower, which causes high-temperature expansion deformation. The bottom of the beam section is larger, the upper part is smaller, and the expansion deformation is restricted by the frame column, which causes additional pressure stress of the upper lower and lower height on the frame beam section. The additional pressure causes the neutral axis of the frame beam to move downwards, which results in upper tension on the frame beam section. The direction of the additional bending moment of the lower compression is opposite to that of the midspan section of the frame beam after normal temperature loading, which decreases the bending moment of the midspan section of the frame beam. After $4 \mathrm{~min}$ of fire, the material performance of the bottom of the frame beam deteriorates because of the high temperature, and under load, the midspan deflection of the frame beam increases, which increases the midspan section bending moment of the frame beam gradually.

Figure 12(a) shows that the bending moment at the end of the frame beam is approximately $-236 \mathrm{kN} \cdot \mathrm{m}$ after normal temperature loading. With an increase of fire time, the bending moment at the end of the frame beam increases slightly, but the increase in amplitude is small. After $4 \mathrm{~min}$ of fire, the bending moment at the end of the frame beam starts to decrease and reaches the fire-resistance limit. The bending moment at the end of the frame beam becomes positive at $218 \mathrm{kN} \cdot \mathrm{m}$ because, in the early stage of fire, the temperature at the bottom of the beam is higher and the temperature at the top is lower. This difference results in an uneven temperature field of the upper low and lower high on the beam section and generates an uneven expansion deformation along the height of the beam section. The expansion deformation is constrained by the frame column at the beam end, which forms an additional bending moment of upper tension and lower compression on the beam end section. This bending moment direction is the same as that of the 

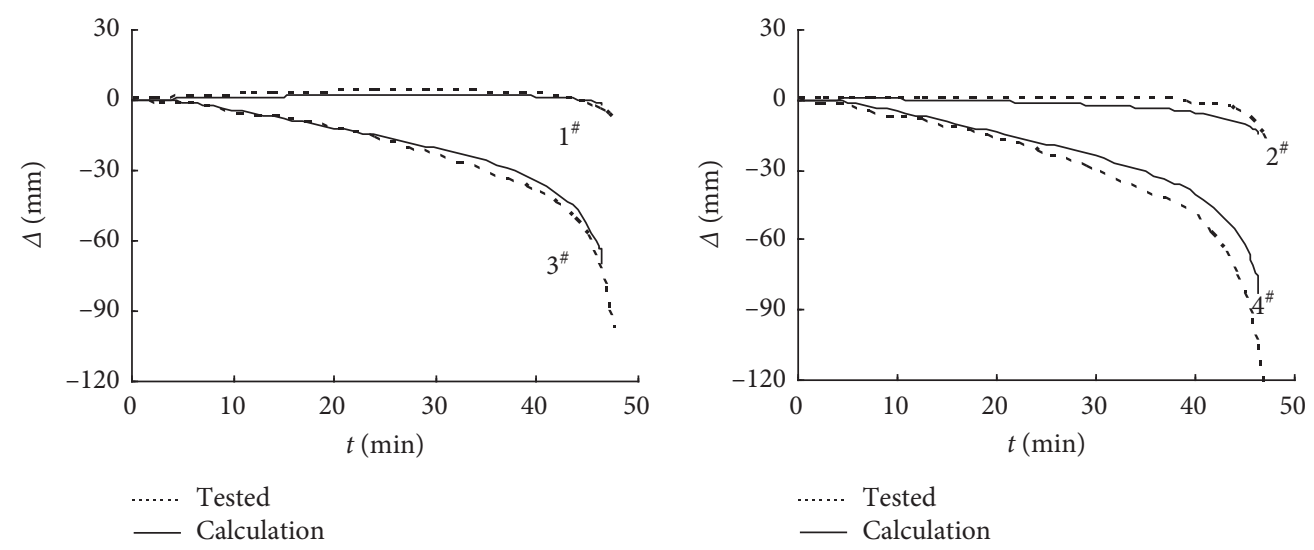

(a)
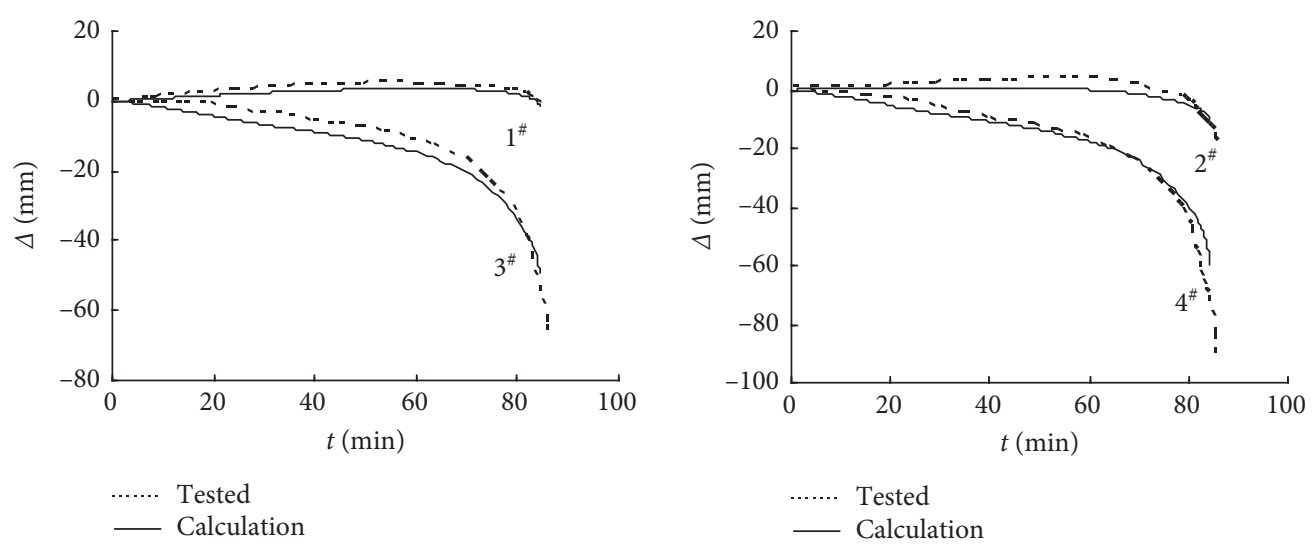

(b)

Figure 7: Vertical displacement curve of models. (a) Model CFSRC-1. (b) Model CFSRC-2.

bending moment at the beam end, so the bending moment of the beam end section increases slightly in the early stage of temperature rise. After $4 \mathrm{~min}$ of fire, under the action of fire and load, the frame beam and column deformation at the edge of the joint area increases, and the joint area rotates in the same direction as the negative bending moment of the beam end section of the frame, which makes the negative bending moment of the beam end decrease. When the beam is exposed to fire for $29 \mathrm{~min}$, the section bending moment in the beam joint area changes from a negative to a positive bending moment, which indicates that the bending moment in the frame beam joint area begins to have an adverse fireresistance effect on the frame beam, increases the positive bending moment in the middle section of the beam span, and then accelerates frame beam failure. During the fire action, the magnitude and direction of the load that acts on the frame beam remains unchanged, so the change in negative bending moment at the end of the beam is similar to the change in midspan bending moment, which is actually the sum of the "second-order bending moment" of the frame beam axial force to the section and the midspan bending moment of the frame beam. Figures 11(b) and 12(b) show that, during the early stage of fire action, because of the short fire time, the expansion effect of the frame beam that is caused by heating is greater than that caused by high- temperature material degradation. The frame beam produces expansion deformation, the frame column has a restraining effect on the frame beam, and the axial pressure of the frame beam section increases with an increase of fire time. At $4 \mathrm{~min}$, degradation of the frame beam material at a high temperature exceeds the expansion at a high temperature, and the axial force in the frame beam tends to decrease. At $20 \mathrm{~min}$ of fire, the thermal expansion of the section steel in the frame beam is significant, which increases the axial force in the frame beam. At the later stage of temperature rise, the bending deformation of the frame column to the inside increases, and the restraint effect of the frame column on the frame beam ends increases, which leads to an increase of axial force in the frame beam. During the fire, the composite column frame structure is unaffected by the horizontal external load, the axial force of the frame beam changes little, and the axial force at the midspan section of the frame beam and the axial force at the end section of the frame beam change synchronously. Figure 11(c) shows that the shear force of the midspan section of the frame beam is about $4 \mathrm{kN}$ during fire action because the dead weight of the frame structure is considered in this calculation example. The dead weight is applied to the geometric center of the component, the frame structure is a plane symmetric structure, and the frame structure is subjected to a 

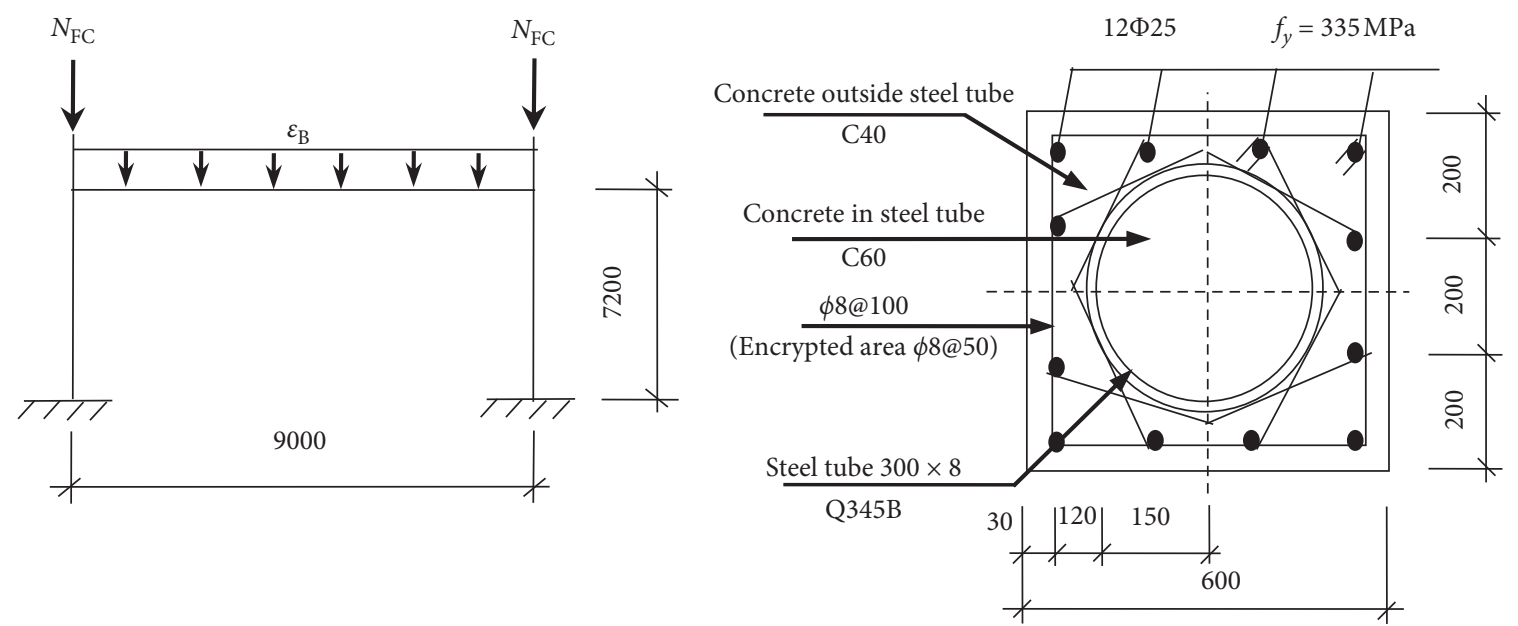

(a)

(b)

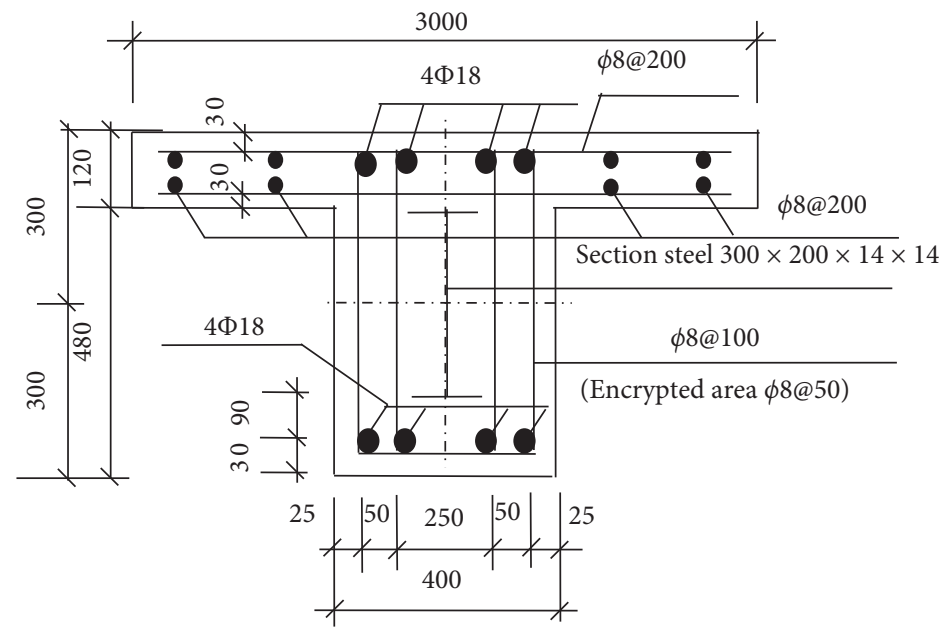

(c)

Figure 8: Geometrical size and details of the analytic model. (a) Plane size and loading method of composite column frame. (b) Crosssection size of composite column. (c) Medium-span section size of section steel beams.

TABLE 1: Fire resistance and failure mode of the frame structure.

\begin{tabular}{lccc}
\hline$n_{c}$ & $n_{b}$ & $t_{\max } / \mathrm{min}$ & Failure mode \\
\hline 0.2 & 0.6 & 296 & The beam broke down \\
0.4 & 0.6 & 59 & The frame beam and frame column were destroyed simultaneously \\
0.6 & 0.6 & 17 & The frame beam and frame column were destroyed simultaneously \\
0.8 & 0.6 & 92 & The frame beam and frame column were destroyed simultaneously \\
\hline 0.6 & 0.2 & 67 & The frame beam and frame column were destroyed simultaneously \\
0.6 & 0.4 & 57 & The frame beam and frame column were destroyed simultaneously \\
0.6 & 0.6 & 39 & The frame beam and frame column were destroyed simultaneously \\
0.6 & 0.8 & The frame beam and frame column were destroyed simultaneously \\
\hline
\end{tabular}

symmetrical additional load. According to the symmetry characteristics of the frame structure, the shear force of the midspan section of the frame beam is half of the dead weight of the frame beam.

Figure 12(c) shows that, during fire action, the shear force at the end of the frame beam is constant and equal to half the sum of the load value and the gravity value of the frame beam. By using the principle of structural symmetry, the shear force at the end of the frame beam is static if the frame beam is selected as the research object. According to the balance principle, the shear force at the end of the frame beam is half the sum of the load value and the gravity value on the beam.

Figures 13 and 14 show the internal force changes of the top and bottom sections of the frame columns. The bending moment is positive for the external tension of the column 


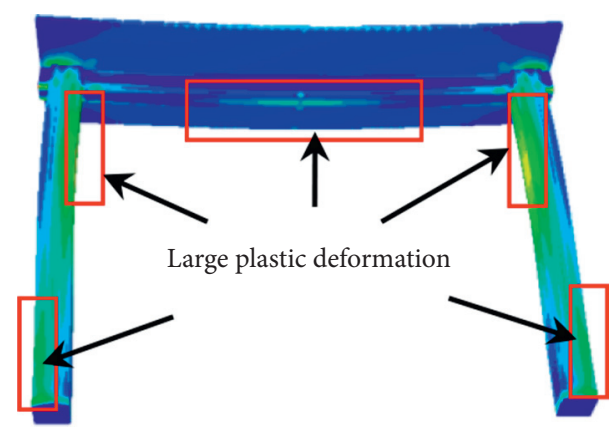

FIgURE 9: Failure mode of the CFSTRC frame.

section and negative for the internal tension; the axial force is positive for the compression of the column and negative for the tension; the shear force is positive for the clockwise rotation of the microend of the column section and negative for the anticlockwise rotation. Figure 13(a) shows that, with an increase of fire time, the bending moment of the bottom section of the frame column increases almost linearly. When the composite column frame structure is damaged, the bending moment of the bottom section of the frame column increases sharply because of the structure instability. Figure 14(a) shows that the bending moment of the column top section increases initially and then decreases and remains unchanged at about $29 \mathrm{~min}$. When the fire-resistance limit is reached, the bending moment of the joint tends to increase because of the rotation deformation of the joint. Figures 13(b) and 14(b) show that, during the fire action, the axial force at the top of the column and the axial force at the bottom of the column remain unchanged because the vertical load of the composite column frame structure remains unchanged during the fire action. The axial force on the top and bottom of the column depends on the sum of the vertical load that acts on the frame and the dead weight of the frame beam and frame column components. Figure 13(b) shows that the axial force on the bottom of the column is about $10310 \mathrm{kN}$, and Figure 14(b) shows that the axial force on the top of the column is about $10240 \mathrm{kN}$, that is, the axial force on the bottom is slight larger than the axial force on the top of the column. The axial force difference is the dead weight of the column, which means that the calculation method in the text is correct. Figure 13(b) shows the axial forces borne by the interior concrete-filled steel tube and the external reinforced concrete of the CFSTRC column during the fire. With an increase of fire time, the axial force that is borne by the external reinforced concrete of the CFSTRC column decreases, and the axial force that is borne by the core concrete-filled steel tube increases. The main reason for this behavior is that the reinforced concrete outside the column is exposed directly to fire, the temperature is high, the mechanical properties of the material degrade, the bearing axial force decreases, and the unloading trend occurs. The concrete-filled steel tube inside the CFSTRC column is far from the fire surface and is protected by the peripheral reinforced concrete at a low temperature. Therefore, the mechanical properties of the material almost do not deteriorate, the core concrete-filled steel tube bears an unloading load of the peripheral reinforced concrete, and the load value increases. After about $23 \mathrm{~min}$, the axial force that is borne by the concrete-filled steel tube inside the CFSTRC column is greater than that borne by the external reinforced concrete, and the change trend tends to be stable. During the fire, the sum of the axial forces that are borne by the concrete-filled steel tube inside the composite column and the reinforced concrete around the composite column remains unchanged, and the magnitude is the axial force at the bottom of the CFSTRC column. Figures 13(c) and 14(c) show that, in the process of fire action, because no load exists in the horizontal direction of the frame structure, the shear force at the bottom of the frame column and the shear force at the section of the frame column in the joint area are equal and change synchronously. The shear force of the frame column section is the same as the axial force of the frame beam section, and the law of change is similar, which also shows that regardless of the change in internal force of the structure, the overall force of the frame structure remains balanced. Figures 11-14 show that the bending moment of the typical section of composite column frame structure changes significantly during fire action, and the overall stress of the composite column frame remains balanced during the fire action process.

\subsubsection{Comparison of Fire Endurance of Composite Column} Frame. Table 2 shows the influence of the fire-load ratio of the columns and beams on the fire endurance and failure mode of the composite column plane frame structure. The influence of the fire-load ratio of the columns and beams on the fire resistance of the CFSTRC columns is also provided. When calculating the fire resistance of the CFSTRC columns, to contrast the fire resistance of the CFSTRC columns with the overall fire resistance of the composite column plane frame structure, the boundary condition of the CFSTRC columns should simulate the boundary condition of the frame columns, that is, the bottom of CFSTRC columns is consolidated, the top of columns is hinged, and the unit of fire resistance is min.

Table 2 shows that, for a column fire-load ratio of 0.2 and a beam fire-load ratio of 0.6 , the beam broke down when the composite column plane frame structure is damaged. Therefore, when the composite column frame reached the fire-resistant limit because the deformation rate of the midspan section of the frame beam is too high, the beam broke down first. Under the fire-load ratio of other beams and columns, when the composite column frame structure reached the fire-resistance limit, the frame beam and frame column were destroyed simultaneously. With the increase of column fire-load ratio, the fire-resistance limit of the CFSTRC columns and the overall fire-resistance limit of the composite column frame structures decreased, and the fireresistance limit of the CFSTRC columns decreased significantly. The column fire-load ratio increased from 0.2 to 0.8 , and the fire-resistance limit of the CFSTRC columns decreased sharply from $582 \mathrm{~min}$ to $38 \mathrm{~min}$. With the increase of the beam fire-load ratio, the overall fire resistance of the composite column frame structure decreased, the fire-load ratio of the beams increased from 0.2 to 0.8 , and the overall 


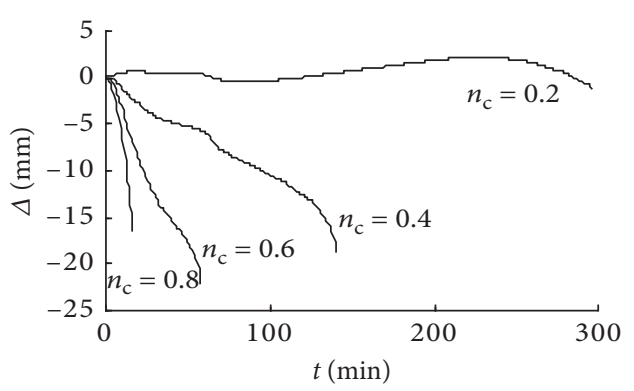

(a)

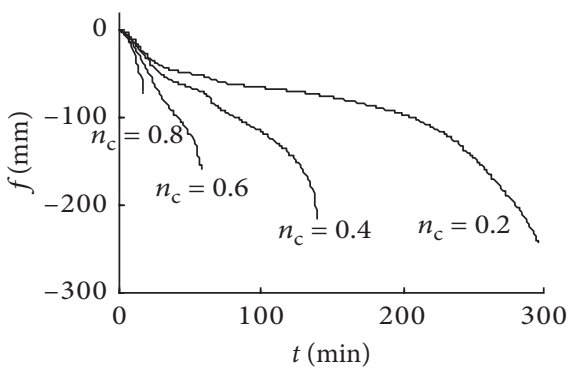

(b)

FIGURE 10: Deformation curves of the CFSTRC frame under different column fire-load ratios. (a) Axial deformation of the top of the column $\left(n_{b}=0.6\right)$. (b) Midspan deflection of beam $\left(n_{b}=0.6\right)$.

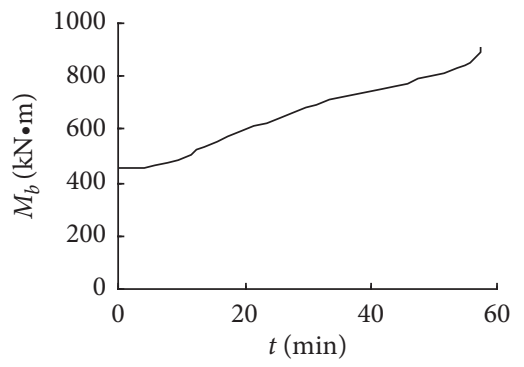

(a)

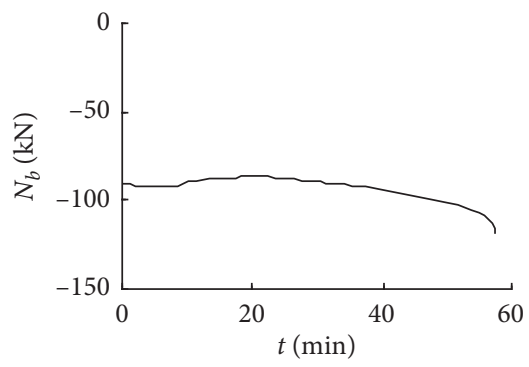

(b)

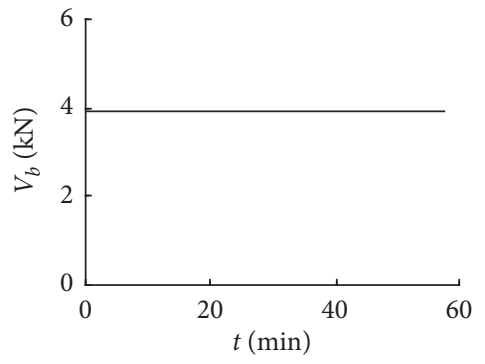

(c)

Figure 11: Internal forces in midspan section of frame beam. (a) Bending moment. (b) Axial force. (c) Shear force.

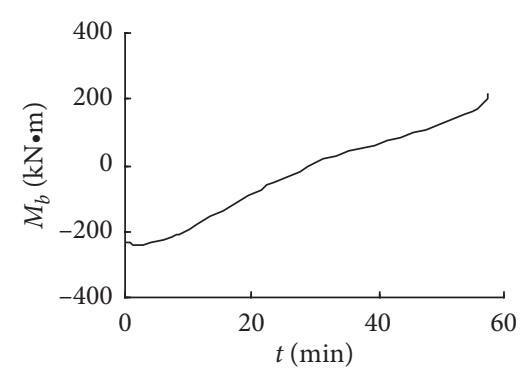

(a)

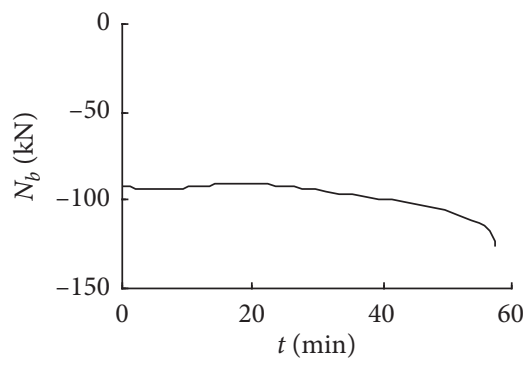

(b)

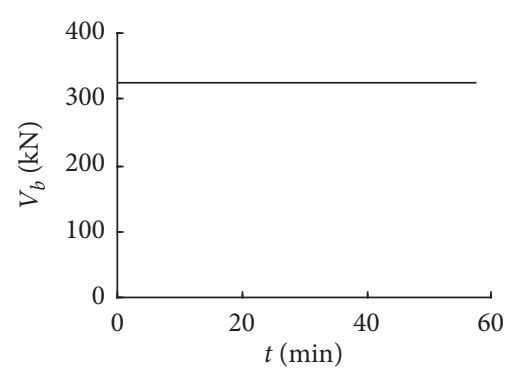

(c)

FIgURE 12: Internal forces of beam on the edge of the joint area. (a) Bending moment. (b) Axial force. (c) Shear force.

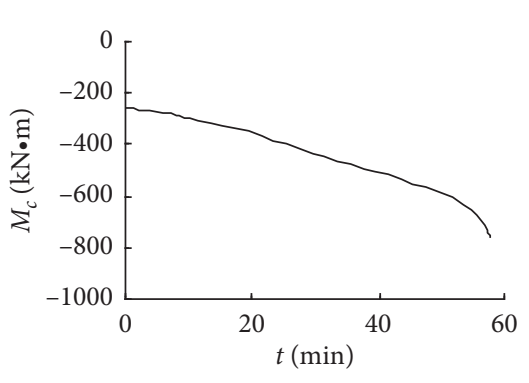

(a)

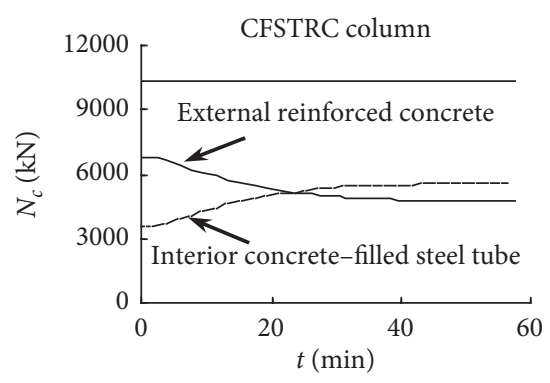

(b)

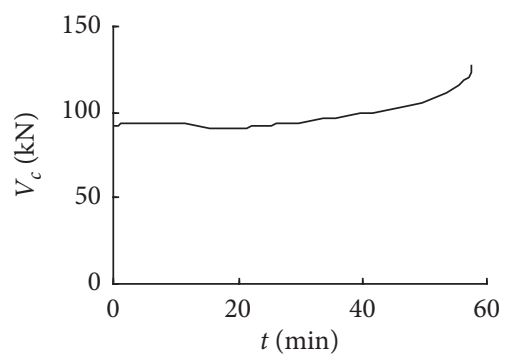

(c)

FIGURE 13: Internal forces of column at the bottom section. (a) Bending moment. (b) Axial force. (c) Shear force. 


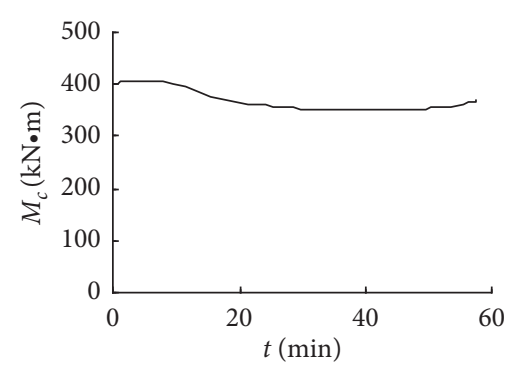

(a)

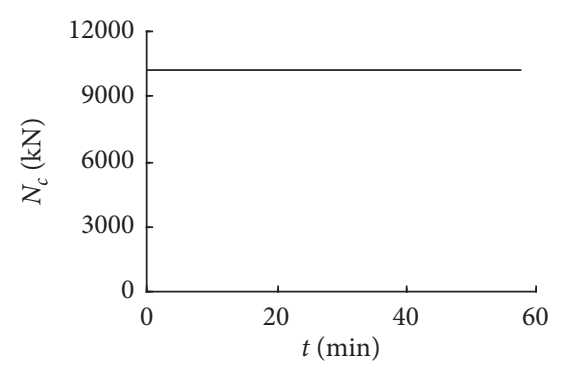

(b)

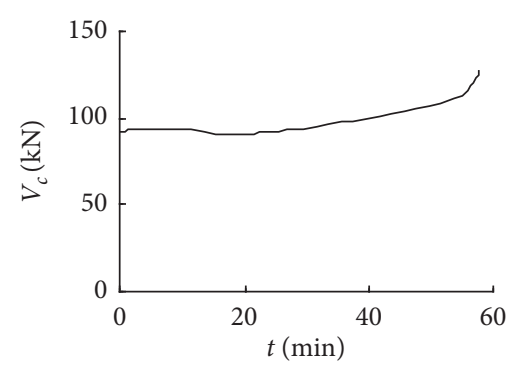

(c)

Figure 14: Internal forces of column on the edge of the joint area. (a) Bending moment. (b) Axial force. (c) Shear force.

TABLE 2: Fire resistance unit: $\min$.

\begin{tabular}{|c|c|c|c|c|}
\hline$n_{c}$ & $n_{b}$ & CFSTRC column & Composite column frame structure & Failure mode of frame structure \\
\hline 0.2 & 0.6 & 582 & 296 & The beam broke down \\
\hline 0.4 & 0.6 & 244 & 139 & The frame beam and frame column were destroyed simultaneously \\
\hline 0.6 & 0.6 & 100 & 57 & The frame beam and frame column were destroyed simultaneously \\
\hline 0.8 & 0.6 & 38 & 17 & The frame beam and frame column were destroyed simultaneously \\
\hline 0.6 & 0.2 & 100 & 92 & The frame beam and frame column were destroyed simultaneously \\
\hline 0.6 & 0.4 & 100 & 67 & The frame beam and frame column were destroyed simultaneously \\
\hline 0.6 & 0.6 & 100 & 57 & The frame beam and frame column were destroyed simultaneously \\
\hline 0.6 & 0.8 & 100 & 39 & The frame beam and frame column were destroyed simultaneously \\
\hline
\end{tabular}

fire resistance of the composite column frame decreased sharply from $92 \mathrm{~min}$ to $39 \mathrm{~min}$. The column fire-load ratio had a greater impact on the overall fire-resistance limit of the composite column frame structure than the beam fire-load ratio.

Table 2 also shows that, with a change in the column fireload ratio and beam fire-load ratio, the overall fire resistance of the composite column frame structure differs from that of a single CFSTRC column, mainly, because the internal force redistribution of the composite column frame structure is caused by interaction between the components during fire action. Compared with the single CFSTRC column, the overall fire resistance of the composite column frame structure was less than that of the CFSTRC column members because the temperature deformation of the composite column frame structure under fire was constrained by adjacent members, and the boundary conditions of the frame columns were changing constantly. The changing boundary conditions usually accelerated composite column frame structure failure, but the boundary conditions were invariable in the single CFSTRC column, so the fire resistance of the composite column frame structure was less than that of the single CFSTRC column.

\section{Conclusions}

A finite-element analysis model of the composite column frame structure was established. The calculated results agreed well with the related experiment data, and the finiteelement analysis mode was able to calculate the mechanical behaviors of the composite column frame structures under fire. Through the analysis that was conducted, the following conclusions can be drawn:
(1) The fire resistance of the composite column frame structure decreased with an increase of frame beam and frame column fire-load ratio, and the frame beam and frame column fire-load ratio had a greater influence on the fire resistance of the frame structure.

(2) Under the action of different fire-load ratios of the frame columns and frame beams, the composite column frame structure which appears to be in the beam broke down to the frame beam and frame column which were destroyed simultaneously. With an increase of frame column fire-load ratio, the failure mode of the composite column frame structure changed from the beam broke down to the frame beam and frame column which were destroyed simultaneously.

(3) During the fire, the bending moment of a typical section of the composite column frame structure changes significantly, whereas the shear force and axial force changed slightly.

(4) The fire-resistance limit of the composite column frame structure is less than that of the single CFSTRC column. The fire-resistance limit of the frame structure should be considered in fire-resistance design in practical engineering.

\section{Data Availability}

No data were used to support the finding of the study.

\section{Conflicts of Interest}

The authors declare that they have no conflicts of interest. 


\section{Acknowledgments}

The research reported in the study was part of the Project 2019-ZJ-971Q sponsored by National Science FoundationYouth of Qinghai Province, project 20170540193 sponsored by Natural Science Foundation of Liaoning Province, project LJYT201908 sponsored by Science Research Fund Project of Liaoning Provincial Department of Education in 2019, and project Grant no. 2018-ZJ-T01 sponsored by Science and technology basic condition platform of Qinghai province. The financial support is highly appreciated.

\section{References}

[1] L. Y. Lin and Q. G. Li, "Design concept and analysis of technical economy for steel tube reinforced concrete column," Building Structure, vol. 38, no. 3, pp. 17-21, 2008.

[2] A. Espinos, L. Gardner, M. L. Romero, and A. Hospitaler, "Fire behaviour of concrete filled elliptical steel columns," Thin-Walled Structures, vol. 49, no. 2, pp. 239-255, 2011.

[3] M. L. Romero, A. Espinos, J. M. Portolés, A. Hospitaler, and C. Ibañez, "Slender double-tube ultra-high strength concretefilled tubular columns under ambient temperature and fire," Engineering Structures, vol. 99, pp. 536-545, 2015.

[4] A. Espinos, M. L. Romero, and D. Lam, "Fire performance of innovative steel-concrete composite columns using high strength steels," Thin-Walled Structures, vol. 106, pp. 113-128, 2016.

[5] M. L. Romero, A. Espinos, A. Lapuebla-Ferri, V. Albero, and A. Hospitaler, "Recent developments and fire design provisions for CFST columns and slim-floor beams," Journal of Constructional Steel Research, vol. 172, pp. 1-21, 2020.

[6] J. P. C. Rodrigues and L. Laím, "Fire resistance of restrained composite columns made of concrete filled hollow sections," Journal of Constructional Steel Research, vol. 133, pp. 65-76, 2017.

[7] R. F. R. Lopes and J. P. C. Rodrigues, "Behaviour of restrained concrete filled square double-skin and double-tube hollow columns in case of fire," Engineering Structures, vol. 216, pp. 1-14, 2020.

[8] X. Mao and V. K. R. Kodur, "Fire resistance of concrete encased steel columns under 3-and 4-side standard heating," Journal of Constructional Steel Research, vol. 67, no. 3, pp. 270-280, 2011.

[9] V. Kodur and N. Raut, "A simplified approach for predicting fire resistance of reinforced concrete columns under biaxial bending," Engineering Structures, vol. 41, pp. 428-443, 2012.

[10] Y. Ding and Z. Y. Wang, "Nonlinear finite element analysis on the fire-resistance capacity of steel frame columns," Journal of Harbin Institute of Technology, vol. 39, no. 12, pp. 1957-1960, 2007.

[11] X. D. Li, Y. L. Dong, and S. P. Cong, "Experimental investigation of behavior of $\mathrm{H}$-section steel beams (end-plate connection) under fire," Journal of Harbin Institute of Technology, vol. 38, no. 6, pp. 978-981, 2006.

[12] X. D. Li, L. G. Chen, L. Jin et al., "Experimental investigation of the behavior of one-story one-bay steel frame in fire," Journal of Harbin Institute of Technology, vol. 41, no. 8, pp. 193-198, 2009.

[13] Z. D. Lu, B. L. Zhu, and Y. X. Yao, "Fire response analysis of reinforced concrete frames," China Civil Engineering Journal, vol. 28, no. 6, pp. 18-27, 1995.
[14] B. Wu and Y. T. Jing, "Experimental study on RC space frames with specially-shaped columns subjected to elevated temperature," Journal of South China University of Technology, vol. 37, no. 6, pp. 129-135, 2009.

[15] G. Y. Wang and Y. M. Li, "Performance of plane frames with concrete filled steel tube columns and steel beams subjected to local fire," Engineering Mechanics, vol. 30, no. 10, pp. 236-243, 2013.

[16] G. Y. Wang, D. M. Zhang, C. C. Zheng et al., "Parameter study on fire performance of concrete filled steel tube column-steel beam plane frames," Engineering Mechanics, vol. 31, no. 6, pp. 138-144, 2014.

[17] W. H. Wang, Behavior of Concrete Filled Steel Tubular Planar Beam-To-Column Frames Subjected to Fire, Fuzhou University, Fuzhou, China, 2008.

[18] Y. H. Bao, J. G. Sun, W. D. Wang, and L. Xu, "FEA on CFSTRC column-reinforced concrete beam plane frames subjected to fire," Journal of Building Structures, vol. 36, no. suppl, pp. 47-53, 2015.

[19] ISO-834, Fire-resistance Tests-Elements of Building Construction: Part 1: General Requirements, International Organization for Standardization, Geneva, Switzerland, 1999.

[20] L. H. Han and T. Y. Song, Fire Safety Design Theory of SteelConcrete Composite Structures, Science Press, Beijing, China, 2012.

[21] T. T. Lie, "Fire resistance of circular steel columns filled with bar-reinforced concrete," Journal of Structural Engineering, vol. 120, no. 5, pp. 1489-1509, 1994.

[22] T. T. Lie and M. Chabot, "A method to predict the fire resistance of circular concrete filled hollow steel columns," Journal of Fire Protection Engineering, vol. 2, no. 4, pp. 111126, 1990.

[23] L. H. Han, Concrete Filled Steel Tubular Structures: Theory and Practice, Science Press, Beijing, China, 3nd edition, 2016.

[24] GB 50936-2014, Technical Code for Concrete Filled Steel Tubular Structures, China Construction Industry Press, Beijing, China, 2014.

[25] JGJ 138-2016, Code for Design of Composite Structures, China Construction Industry Press, Beijing, China, 2016.

[26] CECS 188:2005, Technical Specification for Concrete Filled Steel Tube Composite Column Structures, China Planning Press, Beijing, China, 2005. 